\title{
Impact of Urban Air Pollution on Acute Upper Respiratory Tract Infections
}

\author{
Marcos Abdo Arbex 1,3,4, Silvia Leticia Santiago ${ }^{3}$, \\ Elisangela Providello Moyses ${ }^{3}$, Luiz Alberto Pereiraa, ${ }^{1,2}$ \\ Paulo Hilário Saldiva ${ }^{1}$ and Alfésio Luís Ferreira Braga ${ }^{1,2}$ \\ ${ }^{1}$ Environmental Epidemiology Study Group, \\ Laboratory of Experimental Air Pollution, Pathology Department, \\ University of São Paulo Faculty of Medical Science, \\ ${ }^{2}$ Environmental Exposure and Risk Assessment Group, \\ Collective Health Post-graduation Program, \\ Catholic University of Santos \\ Internal Medicine Post-graduation Program, \\ Federal University of São Paulo Medical School, \\ ${ }^{4}$ Pulmonology Division, Internal Medicine Department, \\ Araraquara University Center Medical School, Araraquara \\ Brazil
}

\section{Introduction}

Epidemiological studies have shown consistent acute adverse health effects of ambient air pollution and in particular, traffic related pollution on the respiratory health system.. Outcomes with different degrees of severity, from sub-clinical lung function changes to respiratory and cardiovascular symptoms, changes in the use of respiratory and cardiovascular medication, impaired activities (e.g., school and work absenteeism), exacerbation of pre-existing diseases such as asthma and chronic obstructive pulmonary disease (COPD), primary care and/or emergency room visits, hospitalizations and mortality have been investigated. Children, the elderly and those with previous cardiorespiratory disease are the most susceptible groups (American Thoracic Society, 2000; Brunekreef \& Holgate, 2002; Berstein et al., 2004; Gouveia \& Maisonet, 2006; Ko \& Huy, 2010; Perez et al., 2010).

In terms of adverse health effects caused by air pollutants, the more severe the clinical manifestation, the less frequent its occurrence. Many people that have been exposed to air pollutants can have sub-clinical effects such as temporary deficits in lung function or pulmonary inflammation while the prevalence of mortality occurs only in a few (Gouveia \& Maisonet, 2006). Acute Respiratory Infections (ARIs) is the most frequent and prominent among the respiratory illnesses that affect children and adults due to the morbidity and mortality associated with this illness. ARIs may be classified into upper (URTIs) and lower (LRTIs) respiratory infections, depending on the affected organs (noses, sinuses, middle ear, larynx, and pharynx in the URTIs and trachea, bronchi, and lungs in the LRTIs) (Bellos et al., 2010). 
URTIs are generally mild in severity and most often are caused by viruses and sometimes, as in some cases of sinusitis and acute otitis media, with a secondary bacterial infection. Usually more severe than URTis, LRTIs episodes occur in children under 5 , the elderly and the immunocompromised individuals (e.g. HIV-infected). From the estimated 4.2 million of LRTIs annual deaths around the world 1.8 million (43\%) occur in children less than 5 . Furthermore, these two groups of ARIs are not mutually exclusive. These clinical conditions frequently coexist during the same episode of respiratory infection and besides, URTIs could precede and lead to LRTIs and exacerbation of pre-existing chronic respiratory diseases. (Chauhan et al., 2005; Bellos et al., 2010; Shusterman, 2011)

The nose and the upper airway, play a sentinel role in the respiratory system. Inspired particles of different aerodynamic sizes tend to impact and interact with the upper airway mucosa. Studies have shown that $\mathrm{PM}_{10}$ can induce alterations in cells of nasal mucosa promoting inflammatory responses (Brunekreef \& Forsberg, 2005). Once trapped in nasal mucous, these particles are transported to the nasopharynx via mucociliary system, being later either swallowed or expectorated. Gaseous/vapor-phase air pollutants can also be removed from inspired air, depending on their water solubility and chemical reactivity (Shusterman, 2011).

Despite growing concerns of ambient air pollution and the burden of URTIs, particularly in major urban centers, research on the effects of pollutants on upper respiratory conditions are relatively sparse. Epidemological studies that have been conducted mainly in children and adolescents, showed in general, effects of pollutants but without evaluating the real impact on different age groups (Jaakkola et al., 1991; von Mutius et al., 1995; Martins et al., 2001; Hajat et al., 2002; Peel et al., 2005; Wong et al., 2006; Larrieu et al., 2009).

In São Paulo, one of the world's most densely populated cities (11.2 million inhabitants), the main source of air pollution is lightweight cars that run on a petrol-ethanol mixture, resulting in the emission of pollutants with a single toxic component. Emergency department (ED) visits related to respiratory disease have been accepted as a sensitive outcome of the short-term effects of air pollution (Peel et al., 2005)

The aim of this study was to estimate the impact of daily air pollution variability on URTIs exacerbation rates, measured via records of daily ED visits, stratifying the analyses by age groups.

\section{Methods}

We conducted an ecological time-series study. Daily records of UTRIs emergency department (ED) visits for patients were obtained from São Paulo Hospital (SPH), an affiliate of the São Paulo Federal University, from 1 February 2001 to 31 December 2003. The UTRIs cases were defined based on criteria listed in the International Classification of Diseases (ICD) 10th revision and took into consideration the primary diagnosis in each ED visit record. Patients with acute nasopharingytis (common cold) (J00), acute sinusitis (J01), acute pharyngitis (J02), acute tonsillitis (J03), acute laryngitis and tracheitis (J04), acute obstructive laryngitis [croup] and epiglottitis (J05), acute upper respiratory infections of multiple and unspecified sites (J06) were included in the study. The SPH is an accredited teaching hospital and its ED treats approximately 50000 patients per year. It has, therefore, been used as a sentinel health service centre for epidemiological studies that aims to evaluate the relationship between air pollution and respiratory morbidity. 
Daily records of particulate matter with an aerodynamic profile $\leq 10 \mu \mathrm{m}\left(\mathrm{PM}_{10}\right)$, carbon monoxide $(\mathrm{CO})$, sulphur dioxide $\left(\mathrm{SO}_{2}\right)$, ozone $\left(\mathrm{O}_{3}\right)$ and nitrogen dioxide $\left(\mathrm{NO}_{2}\right)$ were obtained for the entire analysis period from the São Paulo State Environmental Agency. Thirteen monitoring stations are distributed throughout the city. For each measured pollutant, the average value among stations was adopted as an estimate of city-wide exposure rates. The measurement adopted for $\mathrm{CO}$ (non-dispersive infrared) showed the highest $8 \mathrm{~h}$ moving average at five stations. For $\mathrm{NO}_{2}$ (chemiluminescence) and $\mathrm{O}_{3}$ (ultraviolet), the highest hourly average was measured at four stations. The highest hourly average over a $24 \mathrm{~h}$ period for $\mathrm{PM}_{10}$ (beta radiation) was measured at 12 stations and at 13 stations for $\mathrm{SO}_{2}$ (pulse fluorescenceultraviolet); $24 \mathrm{~h}$ averages were adopted. Small volumes of missing data were replaced by centred moving averages. All pollutants were measured from 00:01 to 00:00. Daily minimum temperatures and daily means of relative air humidity were obtained from the Institute of Astronomy and Geophysics at the University of São Paulo.

The correlations between pollutants and weather variables were estimated using Pearson or Spearman correlation coefficients. The daily number of URTI ER visits was the dependent variable. The independent variables were the daily mean levels of each pollutant $\left(\mathrm{PM}_{10}, \mathrm{SO}_{2}\right.$, $\mathrm{CO}, \mathrm{NO}_{2}$ and $\mathrm{O}_{3}$ ). We also controlled for short-term (ie, days of week) and for long-term (ie, seasonable) and daily climate conditions (minimum temperature and humidity). Counts of daily URTIs ER visits were modeled, for the entire period, using generalized linear Poisson regressions (McCullag \& Nelder, 1989). Analysis was stratified by total UTRIs ED visits and by age (younger than 13, between 13-19, 30-39, 40-65 and older than 65). A Poisson regression model was adopted because ED visits are countable events that exhibit a Poisson distribution. We used natural cubic splines (Green \& Silverman, 1994) to control for season. Splines were used to account for the non-linear dependence of ED visits on that covariate and to subtract the basic seasonal patterns (and long-term trends) from the data. We used 12 degrees of freedom to smooth the time trend. The number of degrees of freedom for the natural spline of the time trend was selected to minimize the autocorrelation between the residuals and the Akaike Information Criterion (Akaike, 1973). After adjusting for the time trend, no remaining serial correlation was found in the residuals, making the use of autoregressive terms unnecessary.

Indicators for day of the week were included in order to control for short-term trends. Respiratory diseases present a nearly linear relationship with weather. Linear terms for temperature and relative humidity were therefore adopted. Effects of minimum temperature were more relevant from lag 0 to lag 2 . Hence, we adopted a 3 -day moving average for the minimum temperature. Relative humidity exhibited a short-duration and small-magnitude effect on URTIs ED visits. We adopted a 2-day moving average for relative humidity. To reduce sensitivity to outliers in the dependent variable, we used robust regression (M-estimation).

The lag structures between air pollution and health were analysed using different approaches and time lags. In this study, we tested the lag from the same day to 6 days before the ED visit using a third-degree polynomial distributed lag model (Green \& Silverman, 1994). Although this imposes constraints, it also allows for sufficient flexibility to estimate a biologically plausible lag structure that controls for better multicollinearity than an unconstrained lag model. The standard errors of the estimates for each day were adjusted for overdispersion. 
Effects of air pollutants were expressed as a percentage increase and as $95 \%$ confidence intervals (95\% CIs) in URTI ED visits. This was due to increases in pollutant concentrations of a magnitude equal to that of the interquartile range (ie, the variation between the $75 \%$ higher and the $25 \%$ lower daily concentrations). All analyses were performed using the SPlus 2000 statistical package for Windows.

\section{Results}

During the study period, 177,325 visits occurred in the emergency unit of São Paulo Hospital and $137,530(72 \%)$ were due to upper respiratory tract infections.

In terms of age groups, emergency visits of children and adolescents younger than 13 years of age were the most frequent, followed by the groups 40 to 65 years, 30 to 39 years, older than 64 years and adolescents from 13 to 19 years old.

Table 1 presents statistical analyses of the main variables adopted in the study.

\begin{tabular}{|c|c|c|c|c|c|c|c|}
\hline \multirow[t]{2}{*}{ Variables } & \multirow[t]{2}{*}{ Mean } & \multirow[t]{2}{*}{$\mathrm{SD}^{*}$} & \multirow[t]{2}{*}{ Minimum } & \multirow[t]{2}{*}{ Maximum } & \multicolumn{3}{|c|}{ Percentage } \\
\hline & & & & & 25 & 50 & 75 \\
\hline $\begin{array}{l}\text { Acute Upper Respiratory } \\
\text { Tract Infections }\end{array}$ & 53.55 & 23.42 & 7.00 & 150.00 & 37.00 & 52.00 & 68.00 \\
\hline \multicolumn{8}{|l|}{ POLLUTANTS } \\
\hline $\mathrm{PM}_{10}\left(\mu \mathrm{g} / \mathrm{m}^{3}\right)$ & 48.71 & 21.87 & 9.62 & 168.98 & 32.29 & 43.88 & 60.55 \\
\hline $\mathrm{SO}_{2} \quad\left(\mu \mathrm{g} / \mathrm{m}^{3}\right)$ & 14.00 & 6.15 & 2.14 & 42.87 & 9.56 & 13.18 & 17.37 \\
\hline $\mathrm{NO}_{2} \quad\left(\mu \mathrm{g} / \mathrm{m}^{3}\right)$ & 120.34 & 49.86 & 30.86 & 390.78 & 81.86 & 113.82 & 150.17 \\
\hline $\mathrm{CO} \quad$ (ppm) & 2.71 & 1.23 & 0.73 & 12.09 & 1.91 & 2.53 & 3.16 \\
\hline $\mathrm{O}_{3} \quad\left(\mu \mathrm{g} / \mathrm{m}^{3}\right)$ & 95.74 & 44.24 & 14.52 & 282.03 & 63.93 & 88.62 & 119.68 \\
\hline \multicolumn{8}{|l|}{ WEATHER } \\
\hline Temperature $\left({ }^{\circ} \mathrm{C}\right) \dagger$ & 15.50 & 3.37 & 3.70 & 21.80 & 13.10 & 15.80 & 18.20 \\
\hline Humidity (\%) $\S$ & 79.17 & 8.43 & 45.54 & 96.60 & 74.50 & 80.00 & 85.00 \\
\hline
\end{tabular}

${ }^{*}$ standard deviation; ${ }^{\dagger}$ minimum temperature; ${ }^{\S}$ relative humidity.

Table 1. Descriptive analyses of daily acute upper respiratory tract infections emergency room visits, air pollutants concentrations, and weather variables along study period.

Surpassing of daily air quality standards was rare among primary pollutants (one day for $\mathrm{PM}_{10}$, two days for $\mathrm{NO}_{2}$, and three days for $\mathrm{CO}$ ). However, for ozone, the one hour moving average standard was surpassed 52 times along the period.

Low temperature is rare in São Paulo as observed in the studied period. In terms of relative humidity, it was not observed any daily record below $40 \%$.

We explored air pollutants effects on daily number of upper respiratory tract infections ER visits using pollutant-specific models. Figure 1 presents the effects of increases in $\mathrm{PM}_{10}$ daily levels on the outcome for the entire group of patients. 


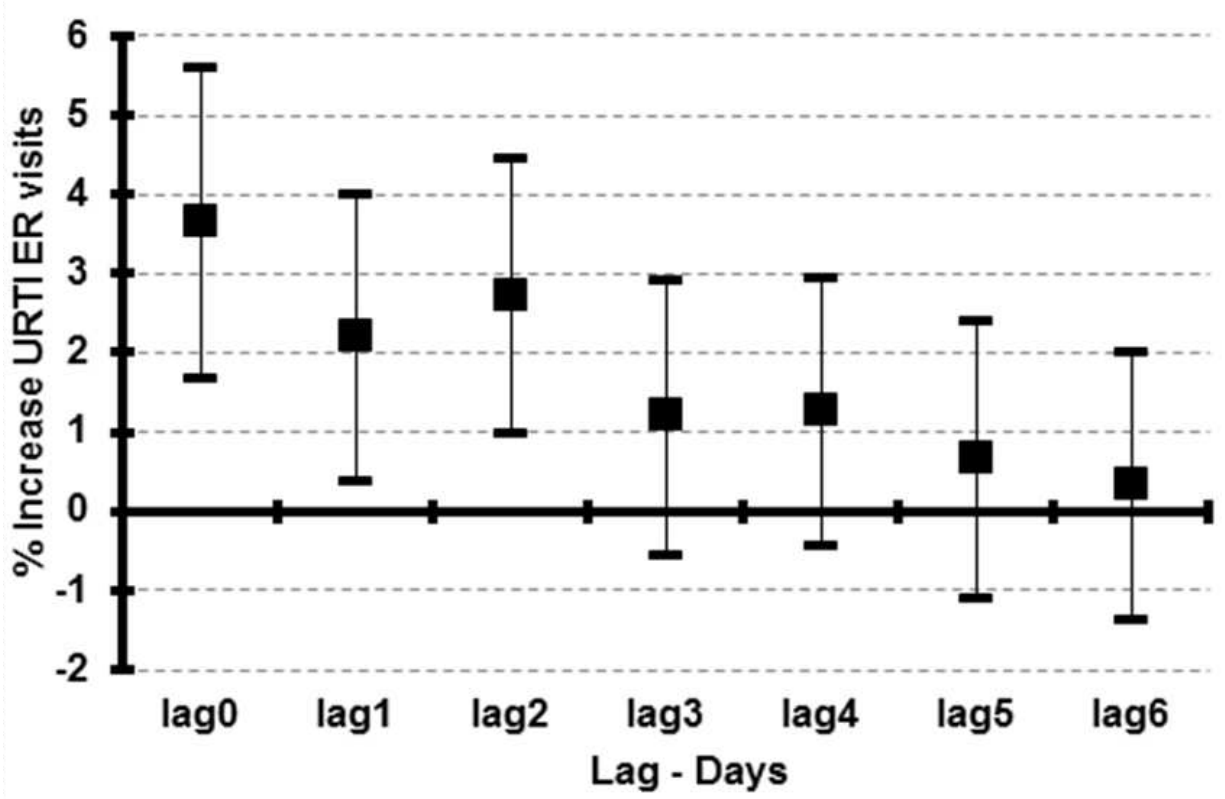

Fig. 1. Percentage increases and $95 \%$ confidence intervals on daily upper respiratory tract infections ER visits due to interquartile range increases in PM10 daily concentrations (28.26 $\mu \mathrm{g} / \mathrm{m} 3)$.

An interquartile range increase in $\mathrm{PM}_{10}$ concentration $(28.26 \mu \mathrm{g} / \mathrm{m} 3)$ led to increases in URTI ER visits. The effect was acute, starting at the same day of exposure (lag0) and remaining for two consecutive days. After that, there was a smooth decline of the effect magnitude until the sixtieth day after the exposure. It was observed a three-day cumulative effect (from lag0 to lag2) of $8.9 \%$ (95\% CI: 5.7-12.0). When this analysis was stratified by age group it was observed two patterns of lag structure (Figure 2).

The youngest group presented a pattern of effect that was different from the others. Interquartile range increase in $\mathrm{PM}_{10}(28.26 \mu \mathrm{g} / \mathrm{m} 3)$ was associated to an acute effect, starting at the same day of exposure and remaining for three consecutive days. As the most prevalent age group, its effect pattern was determinant for the effect pattern observed for the entire group. The other age groups presented similar lag structures, with acute effects only at the same day of exposure without lagged effects. The four-day cumulative effect observed for the youngest group reached 13.0\% (95\% CI: 8.3-17.8) increase in URTI ER visits. In the group of people from 45 to 65 years old it was not observed statistically significant effects, although the pattern of the lag structure seems to be similar to those observed for adolescents, adults, and elderly.

Only CO presented a lagged effect (lag 2,3,4) on the outcome for the elderly group. Remaining gaseous pollutants presented similar patterns of acute effects (in the same day of exposure). When the analyses where stratified by age groups the pattern of effect remained the same as observed for the entire group, differently from that observed for PM10 effects. Also, in terms of age groups, it was impossible to define an age-dependent pattern of susceptibility for gaseous pollutants. 

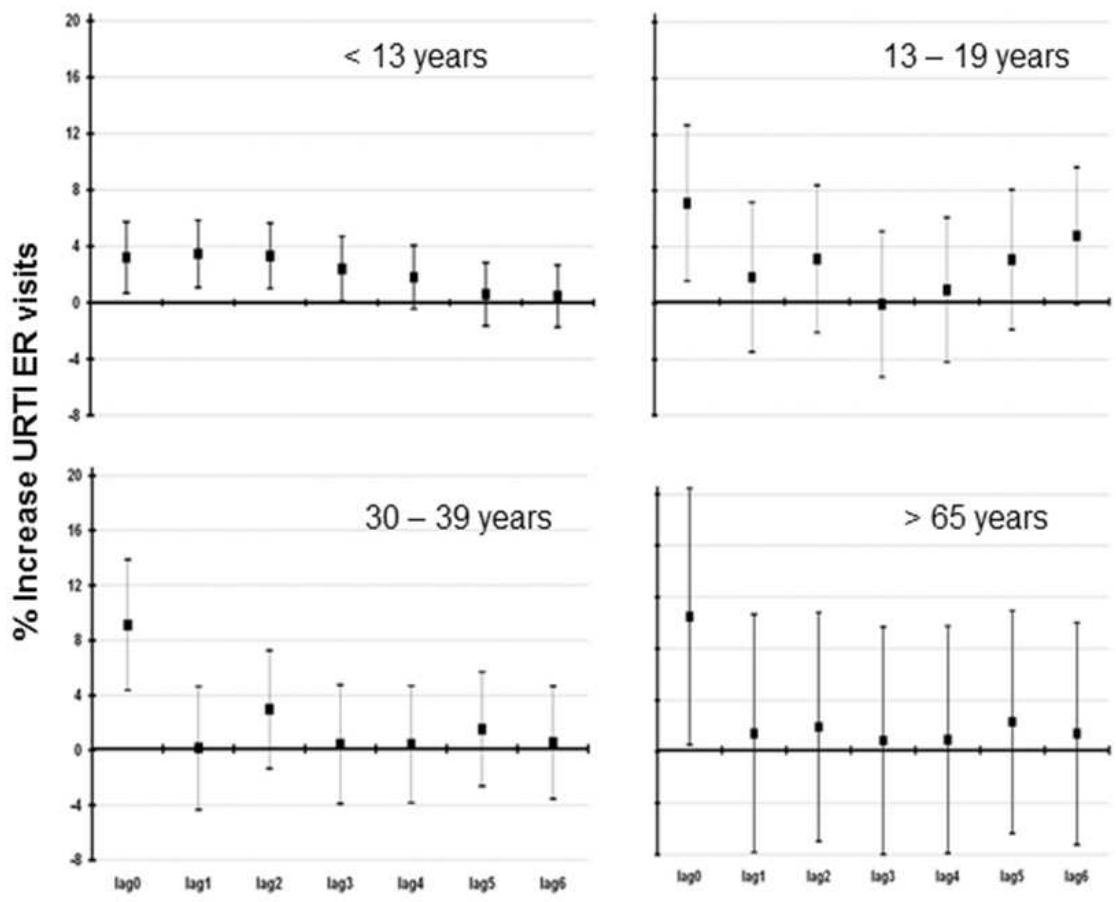

\section{Lag - Days}

Fig. 2. Percentage increases and $95 \%$ confidence intervals on daily upper respiratory tract infections ER visits due to interquartile range increases in $\mathrm{PM}_{10}$ daily concentrations (28.26 $\mu \mathrm{g} / \mathrm{m} 3$ ) according to different age groups (younger than 13 years, from 13 to 19 years, from 30 to 39 years, and older than 65 years).

Table 2 presents the estimates of effects and lag structures for gaseous pollutants and URTI ER visits.

\begin{tabular}{ccccc}
\hline \multirow{2}{*}{ Days } & \multicolumn{4}{c}{$\begin{array}{c}\text { URTI ER Visits Percentage Increase } \\
(95 \% \text { Confidence Intervals })\end{array}$} \\
\cline { 2 - 5 } & $\mathrm{CO}$ & $\mathrm{NO}_{2}$ & $\mathrm{O}_{3}$ & $\mathrm{SO}_{2}$ \\
& $(1.25 \mathrm{ppm})$ & $(68.30 \mu \mathrm{g} / \mathrm{m} 3)$ & $(55.76 \mu \mathrm{g} / \mathrm{m} 3)$ & $(7.81 \mu \mathrm{g} / \mathrm{m} 3)$ \\
\hline Lag0 & $0.8(-0.6 ; 2.2)$ & $4.3(2.2 ; 6.4)$ & $3.4(1.2 ; 5.6)$ & $0.5(0.2 ; 0.7)$ \\
Lag1 & $0,2(-1.1 ; 1.5)$ & $0.5(-1.6 ; 2.6)$ & $-0.3(-2.3 ; 1.7)$ & $-1.1(-3.1 ; 1.0)$ \\
Lag2 & $1,5(0,2 ; 2,8)$ & $0.2(-1.9 ; 2.2)$ & $-0.2(-2.0 ; 1.7)$ & $1.5(-0.4 ; 3.3)$ \\
Lag3 & $0,6(-0.7 ; 1.9)$ & $-0.2(-2.2 ; 1.8)$ & $0.5(-1.3 ; 2.3)$ & $-0.3(-2.2 ; 1.6)$ \\
Lag4 & $-0.1(-1.4 ; 1.3)$ & $-0.5(-2.5 ; 1.5)$ & $0.6(-1.2 ; 2.4)$ & $0.0(-1.8 ; 1.8)$ \\
Lag5 & $-0.1(-1.4 ; 1.2)$ & $0.3(-1.8 ; 2.3)$ & $1.3(-0.5 ; 3.0)$ & $0.1(-1.7 ; 1.9)$ \\
Lag6 & $0.1(-1.2 ; 1.4)$ & $0.7(-1.3 ; 2.7)$ & $0.1(-1.7 ; 1.8)$ & $0.7(-1.2 ; 2.5)$ \\
\hline
\end{tabular}

Table 2. Percentage increases and $95 \%$ confidence intervals on daily upper respiratory tract infections ER visits due to interquartile range increases in daily concentrations of $\mathrm{CO}(1.25 \mathrm{ppm})$, $\mathrm{NO}_{2}(68.30 \mu \mathrm{g} / \mathrm{m} 3), \mathrm{O}_{3}(55.76 \mu \mathrm{g} / \mathrm{m} 3)$, and $\mathrm{SO}_{2}(7.81 \mu \mathrm{g} / \mathrm{m} 3)$ for the entire patients group. 


\section{Discussion}

We have shown that $\mathrm{PM}_{10}$ presented a more consistent adverse effect on respiratory tract evaluated in terms of upper respiratory tract infections ER visits than gaseous pollutants and that this effect has both lag structure and age-dependent magnitude.

In this investigation we adopted the time-series design with the most used regression model to investigate acute effects of air pollutants. Poisson regression and polynomial distributed lag models have been largely tested and they have shown consistent results and less susceptibility to bias.

We adopted upper respiratory tract infection as an endpoint because it is the most common disease in humans that lead patients to medical services. Among them, the emergency departments receive most of those cases (Fendrick et al.,2003; Footitt \& Johnston, 2009). The incidence of acute URTIs is inversely proportional to age. On average, the youngest children have 6-8 and adults 2-4 per year (Heikkinen \& Jarvinen, 2003).

The effect of air pollutants on health are more demonstrated on children and on the elderly and the evidence of an effect among adults in the general population is more limited (Cesarone et al., 2008). More refined assessment, including analysis of subgroup defined by specific illness or ages, or of air pollutants not routinely monitored, has been limited by study size and available air quality and health outcome data. (Peel et al., 2005). In this study we took advantage of obtaining data at the Federal University Hospital that attends to a considerable number of patients in the most populous city in Brazil with an official network of air monitoring at 14 substations. This fact has allowed us to stratify our results by age group and by air pollutants.

Viruses are the causal pathogens in most upper respiratory tract infection cases, with fewer than $10 \%$ of the cases caused by bacteria. The viral pathogens primarily associated with upper respiratory tract infections include picornaviruses (notably, rhinoviruses and enteroviruses), coronaviruses, adenoviruses, parainfluenza viruses, influenza viruses, and respiratory syncytial viruses. (Fendrick et al., 2003; Heikkinen \& Jarvinen, 2003) Infections caused by influenza (ICD 10th J10-J11) is not included in the current study and will be presented elsewhere.

Non- influenza viral respiratory tract infection (VRTI) compromises the overall health status of the individual and produce high morbidity. The average length of an episode is about 7 days and one quarter of the cases can reach 14 days. The magnitude of VRTIs impact on public health can be scaled through the study of The National Centre for Health Statistics (USA), which showed that in the United States of America around 500 million non-influenza viral upper respiratory infections occur annually, resulting in a loss of 40 billion US dollar costs and with 40-100 million school and work days lost to absenteeism. (Fendrick et al.,2003; Footitt \& Johnston, 2009 ). In the United Kingdom, treatment of cough, symptom usually associated to viruses, in non-asthmatic pre-school children cost at over 30 million pounds annually. (Hollinghurst et al., 2008).

The airway epithelium acts as the first defense against respiratory pathogens, as a physical barrier, with the mucociliary system and its immunological functions. It initiates multiple innate and adaptive immune mechanisms for efficient antiviral responses. The interaction between respiratory pathogens and airway epithelial cells results in production of substances, including type I and III interferons, lactoferrin, $\beta$-defensins, and nitric oxide, and also in the production of cytokines and chemokines, which recruit inflammatory cells and influence adaptive immunity. These defense mechanisms usually result in rapid pathogens 
clearance. (Becker et al., 2005; Vareilleet et al., 2011). In addition alveolar macrophages (AMs) play a key role in the defense against respiratory infection. At least three properties of AMs play key antimicrobial roles, i.e. the production of inflammatory cytokines, reactive oxidant species (ROS) and interferon (Castranova et al., 2001). Besides macrophages can inhibit viral replication and also limit viral infections by removing the debris of destroyed cells and by presenting viral antigens to T lymphocytes (Mei et al., 2005).

Once installed in the airway epithelium, viral infections can damage the barrier function leading to enhanced absorption of allergens and/or irritants across the airway wall promoting inflammation. Conversely, experimental results have shown that intact epithelium is more resistant to infection of human respiratory viruses. Consequently, external agents such as allergens and pollutants that damage airway epithelium could increase susceptibility to infection and/or lead to more-severe infections. (Gern, 2010)

The mucosa of the upper respiratory (URT) is exposed to almost all of the airborne irritating agents. Depending on both, chemical composition and concentration, these pollutants could alter the morphological patterns of this mucosa at subcellular level and lead to acute and chronic adverse effects that include hypersecretory reaction of the mucous gland and globet cells, decrease of the cilia number and size and loss of the normal pseudo-stratified pattern of the epithelium (Gulisano et al., 1997). Furthermore, experimental evidence suggests that exposures to ambient air pollution may adversely affect lung defense functions such as aerodynamic filtration, mucociliary clearance, particle transport, and detoxification by alveolar macrophages (Mei et al., 2005).

In terms of criteria air pollutants, studies have shown that both particulate and gaseous pollutants can act all over the airways to initiate and exacerbate cellular inflammation. Inflammatory cells have been seen in bronchoalveolar lavage or nasal washes of asthmatics and not-asthmatic patients exposed to diesel exhausts, ozone, sulphur dioxide and nitrogen dioxide in chambers studies or after nasal provocation challenges, respectively (Bernstein et al., 2004).

Coarse particles deposit in the upper airways of the lungs and are associated with increased cytotoxicity and proinflammatory cytokines interleukin-6 and interleukin-8 (Mei et al., 2005). Upon contact with particles AMs are activated, and produce a large quantity of reactive oxygen species (ROS) from various enzymatic sources (Huang et al., 2008). Particulate matter (PM) exposure may also increase or decrease antioxidant defense mechanisms in the lung, which further modulates oxidative stress and enhances pulmonary and systemic inflammation (Huang et al, 2008). Furthemore, PM inhibit the pulmonary production of interferon in response to viral exposure (Castranova et al, 2001). Experimental study showed that exposure to coarse particles significantly exacerbated pulmonary infection in mice (Mei et al., 2005). The suppressive effects of PM on production of antimicrobial agents result in pulmonary susceptibility to both viral and bacterial infection, as demonstrated in animal models. (Castanova et al, 2001).

Inhalation of ozone $\left(\mathrm{O}_{3}\right)$ leads to disruption of epithelial barrier, affects the mucociliary clearance and can induce production of proinflammatory factors. $\mathrm{O}_{3}$ is cytotoxic to macrophages and can modify the macrophage and neutrophil paghocytosis (Hollingsworth et al., 2007). These effects can cause susceptibility to viral and bacterial infections. Two age groups, the children and elderly, are particularly vulnerable to low levels of inhaled $\mathrm{O}_{3}$ but its effects can be also noted in the other age groups (Hollingsworth et al., 2007). In this study we did not observe lagged effects of ozone or differentiation by age groups. 
The health effects of nitrogen dioxide $\left(\mathrm{NO}_{2}\right)$ exposure may result from both the direct oxidant effects of the pollutant and from increasing airway susceptibility to other challenges, including respiratory virus infection. $\mathrm{NO}_{2}$ causes a cascade of events, beginning with injury and inflammation of the distal airway epithelium, recruitment of $\mathrm{T}$ lymphocytes from blood to the airways, and increased susceptibility of the injured epithelial cells to viral infection (Frampton et al., 2002). Also, $\mathrm{NO}_{2}$ cause reduction in ability to macrophage fagocytose and ciliary diskenesis (Chauhan et al., 2005). In this study the $\mathrm{NO}_{2}$ effects were small and unlikely to be of clinical significance for healthy subjects. Also, effects were acute, on the same day of exposure, without differentiation by age groups. Presence of comorbidities may increase the susceptibility of some age groups to $\mathrm{NO}_{2}$ effects.

Sulphur dioxide $\left(\mathrm{SO}_{2}\right)$ is a respiratory tract irritant that has been shown to cause acute respiratory health effects including cough, bronchoconstriccion and decreased lung function in controlled human exposures. In high concentrations, $\mathrm{SO}_{2}$ exposure can result in significant airway injury (Chen et al., 2007). Experimental studies have shown that $\mathrm{SO}_{2}$ causes edema, loss of cilia, epithelial thinning, and epithelial desquamation in the olfactory epithelium in mice (Min et al., 1994), damage to the epithelium of the airways and slowing of ciliary transport of mucus (Lippmann \& Ito, 2005) and reduced resistance of female mice to infection by aerosol inoculation with Klebsiella pneumoniae (Azoulay-Dupuis et al., 1982). $\mathrm{SO}_{2}$ levels have declined in São Paulo over the last decades. However, we have observed adverse effects on health even under this situation (Arbex et al., 2009). In this study, the smallest effect was observed for $\mathrm{SO}_{2}$ exposure and no effect modification was observed in age groups analyses.

In urban centers carbon monoxide (CO) emissions have declined significantly since the introduction of catalytic converters for motor vehicles (Chen et al., 2007). However, the health risks of exposure to these low levels even below to current standards could produce a considerable public health burden particularly for persons with cardiovascular disease (Bell et al., 2009). Investigators have linked short-and long-term CO exposure mainly with cardiovascular events (Chen et al., 2007; Bell et al., 2009).

Our results have shown that the age group most affected by exposure to particles, $\mathrm{NO}_{2}$ and $\mathrm{O}_{3}$ was children.

Three repeated cross-sectional studies of a total of 7,611 East German children aged 5-14 yrs during 1992-1993, 1995-1996, and 1998-1999 found a statistical significant age-adjusted decrease for bronchitis (54.2 versus $38.0 \%$ ), otitis media (30.7 versus $26.7 \%$ ), sinusitis (4.6 versus $2.3 \%$ ), frequent colds (36.7 versus $28.5 \%$ ) and morning cough (13.4 versus $12.2 \%$ ) in parallel to an improvement of annual means of $\mathrm{SO}_{2}(60$ versus $8 \mu \mathrm{g} \mathrm{m}-3)$ and TSP (56 versus 29\%) (Heinrich et al., 2002).

Joaakkola et al. (1991) reported an increased prevalence of URTIs in infants and children living in city polluted by moderate levels of $\mathrm{PM}_{10}, \mathrm{NO}_{2}$ and $\mathrm{SO}_{2}$ as compared to children of a clean air region and von Mutius et al. (1995) have shown that high concentrations of SO2 and moderate levels of particulate matters and $\mathrm{NO}_{2}$ are associated with an increase risk of developing upper respiratory symptoms in childhood.

Peel et al. (2005) in a time-series study have shown that URTIs visits, mainly in infants and children, were positively associated with levels of $\mathrm{PM}_{10}, \mathrm{O}_{3}, \mathrm{NO}_{2}$ and $\mathrm{CO}$. Despite our study not showing relationship between CO and URTIs in children the lag structure of studies are very similar. 
Study conducted in Finland have demonstrated that higher levels of SO2 and NO2 were associated with an increase number of URTIs (Ponka, 1990) and study conducted in Hong Kong significant association between first visit for URTI and an increase in the concentration of $\mathrm{NO}_{2}, \mathrm{O}_{3}, \mathrm{PM}_{10}, \mathrm{PM}_{2,5}$ was observed, but not $\mathrm{SO}_{2}$ (Wong et al., 2006). However the models of the studies have different design from ours since they do not explore lag and age groups.

Our findings are consistent with Hajat et al (2002), who carried out a study in London, UK. They found a stronger association for $\mathrm{PM}_{10}$ for upper respiratory diseases on general practitioner: $5.7 \%$ for a $31 \mu \mathrm{g} \mathrm{m}-3$ change in $\mathrm{PM}_{10}$ in adults aged $15-64 \mathrm{yrs}$, and $10.2 \%$ in adults aged $\geq 65$ yrs. However, they estimated that a $18 \mu \mathrm{g} \cdot \mathrm{m}-3$ increase in $\mathrm{SO}_{2}$ resulted in a $3.5 \%$ increase in childhood consultations at family practices while in our study the age group more affected by $\mathrm{SO}_{2}$ exposure was the adults aged between 30 and 65 years.

Similar to our study lag structure, Laurie et al. (2009) have demonstrated the risk of medical home visits in Bordeax, France and upper respiratory diseases was significantly increased by $1.5 \%(\mathrm{CI} 0.3,2.7)$ during 3 days following a $10-\mu \mathrm{g} / \mathrm{m} 3$ increase in $\mathrm{PM}_{10}$ levels.

Cesarone et al. (2008) have shown that indices of exposure to traffic-related air pollution were consistently associated with an increased risk of rhinitis in adults in Rome, Italy. However, different from our study, the authors suggest that the main mechanism was due to allergic process.

Different from previous study, we found an association between increase in CO levels and emergency room visits for URTIs in elderly people at lag $2,3,4$. Whereas the main effect of carbon monoxide is on the cardiovascular system, our hypothesis is if the IRTIs could lead to cardiovascular injury in sensitive people.

Despite certain minor differences between our study and those mentioned above, all agree on one major point: urban air pollutants are hazardous and could lead to URTIs. The minor disagreements between age groups and pollutant-specific effects can most likely be attributed to study-specific design characteristics.

\section{Conclusion}

This study showed that air pollutants exposure in general, and $\mathrm{PM}_{10}$ in special, can increase ED visits due to upper respiratory tract infections and that this effect can be modified by age group. Upper respiratory tract infections cannot be considered severe health outcomes. However, it is one of the most frequent groups of respiratory diseases and affects different age groups, increasing cost of medical treatments. Despite the well known susceptibility of the extreme age groups to air pollutants exposure there are other age groups that seem to present pollutant-specific susceptibility, enlarging the burden of air pollutants on health. Despite the observed differences on effects estimates by pollutants, in the outdoor environment people are exposed to a mixture of pollutants and pollutant-specific effects that is really difficult to estimate in the outdoor environment.

We believe that this study may support efforts to limit air pollution emissions to stricter standards than those currently adopted in Brazil. In addition, despite the improvement in car engines and the consequent reduction in emissions, the number of cars has increased over the last decade, bringing more vehicles to the streets every day. Monitoring this scenario will require new studies that evaluate frail population groups and analyzing effect modifiers. 
Finally, we identified a clear association between air pollution and daily URTIs-related emergency department visits for individuals with different age groups in the city of Sao Paulo, Brazil. Air pollution remains an under-evaluated cause of URTIs exacerbation. Primary pollutants, which in São Paulo are generated mainly by cars, are among those factors that must be addressed in order to minimize the risks to public health.

\section{References}

American Thoracic Society. (2000). What constitutes an adverse health effect of air pollution? American Journal of Respiratory and Critical Care Medicine, Vol. 165, No. 2, pp. 665-673, ISSN1073-449X

Akaike, H. (1973). Information theory and an extension of the maximum likelihood principal. In: 2nd International Symposium on Information Theory, Petrov BN, Csaki F, pp. 267-281, Akademiai Kiado, Budapest

Arbex M.A.; de Souza Conceição, G.M.; Cendon, S.P.; Arbex, F.F.; Lopes, A.C.; Moysés, E.P.; Santiago, S.L.; Saldiva, P.H.; Pereira, L.A. \& Braga, A.L.F. (2009). Urban air pollution and chronic obstructive pulmonary disease. Jounal of Epidemiology and Community Health, Vol. 63, No. 10, pp. 777-783, ISSN 0143-0005X

Azoulay-Depuis, E.; Bouley, G. \& Blayo, M.C. (1982) Effects of sulfur dioxide on resistance to bacterial infection in mice. Environmental Research, Vol. 29, No. 2, pp. 312-319, ISSN 0013-9351

Becker, S.; Mundandhara, S.; Devlin, R.B. \& Madden, M. (2005). Regulation of cytokine prod uction in human alveolar macrophages and airway epithelial in response to ambient air pollution particles: Further mechanists studies. Toxicology and Applied Pharmacology, Vol. 207, suppl. 2, pp. S269-S273, ISSN 0041-008X.

Bell, M.L.; Peng, R.D.; Dominici, F. \& Samet, J.M. (2009). Emergency hospital admissions for cardiovascular diseases and ambient levels of carbon monoxide. Circulation, Vol. 120, No. 11, pp. 949-955, ISNN 0009-7322

Bellos, A.; Mulholland, K.; O’Brien, K.L.; Qasi, S.A.; Gayer, M. \& Checci, F. (2010). The burden of acute respiratory infections in crisis-affected populations: a systematic review. Conflict and Health, Vol. 4, No. 3, pp. 1-12, ISNN 1752-1505

Bernstein, J.A.; Alexis, N.; Barnes, C.; Bernstein, I.L.; Bernstein, J.A.; Nel, A.; Peden, D.; DiazSanchez, D.; Tarlo, S.M. \& Williams, P.B. (2004). Health effects of air pollution. Jounal of Allergy and Clinical Immunology, Vol. 114, No. 5, pp. 1116-1123, ISSN 00916749

Brunekreef, B. \& Holgate, S.T. (2002). Air pollution and health. Lancet Vol. 360, No. 9341, pp. 1233-1242, ISSN 0140-6736

Castranova, V.; Ma, J.Y.V.; Yang, H.M.; Antonini, J.M.; Butterworth, L.; Barger, M.W.; Roberts, J. \& Ma, J.K.H. (2001). Effect of exposure to diesel exhaust particles on the susceptibility of the lung to infection. Environmental Health Perspective, Vol. 109, suppl. 4, pp. 609-612, ISSN 0091-6765

Cesarone, G.; Badaloni, D.P.; Forastieri, F. \& Perucci, C.A. (2008). Comparison between various indices of exposure to traffic-related air pollution and their impact on respiratory health in adults. Occupational and Environmental Medicine, Vol. 65, No. 10, pp. 683-690, ISSN 1470-7926 
Chauhan, A.; Chatterjee, A. \& Johnston, S. (2005). Acute respiratory infections. In: Effects of air pollution on children health and development. A review of the evidence, European Center of Environmental and Health, pp. 44-69, World Health Organization, Bonn.

Chen, T.M.; Gokhale, J.; Schofer, S. \& Kuschner, W.G. (2007). Outdoor air pollution: Nitrogen dioxide, sulfur dioxide, and carbon monoxide health effects. The American Journal of the Medical Sciences, Vol. 333, No. 4, pp. 249-256, ISSN 0002-9629

Fendrick, A.M.; Monto, A.S.; Nightengale, B. \& Sarnes, M. (2003). The economic burden of non-influenza-related viral respiratory tract infection in the United States. Archives of Internal Medicine, Vol. 163, No. 4, pp. 487-494, ISSN 0003-9926

Footitt, J. \& Johnston, S.L. (2009). Cough and viruses in airways disease: mechanisms. Pulmonary Pharmacology and Therapeutics, Vol. 22, No. 2, pp. 108-113, ISSN 1094-5539

Frampton, M.W.; Boscia, J.; Roberts Jr, N.J.; Azadniv, M.; Torres, A.; Cox, C.; Morrow, P.E.; Nichols, J.; Chalupa, D.; Frasier, L.M.; Gibb, F.R.; Speers, D.M.; Tsai, Y. \& Utell, M.J. (2002). Nitrogen dioxide: effects on airways and blood cells. American Journal of Physiology - Lung Cellular and Molecular Physiology, Vol. 282, No. 1, pp. L155-L165, ISSN 1040-0605

Gern, J.E. (2010). The ABCs of rhinoviruses, wheezing, and asthma. Journal of Virology, Vol. 84, No. 15, pp. 7418-7426, ISSN 0022-538X

Gouveia, N.C. \& Maisonet, M. (2005). Health effects of air pollution: an overview. In: Air quality guidelines. Global Update 2005, World Health Organization, pp. 87-103, WHO Office for Europe, ISBN 92-890-2192-6, Copenhagen

Green, P.J. \& Silverman, B.J. (1994). Non parametric regression and generalized linear models: a roughness penalty approach, Chapman \& Hall, London

Gulisano, M.; Marceddu, S.; Barbaro, A.; Pacini, A.; Buiatti, E.A.; Martini, A.P. \& Pacini P. (1997). Damage to the nasopharyngeal mucosa induced by current levels of urban air pollution: a field study in lambs. European Respiratory Journal, Vol. 10, No. 3, pp. 567-572, ISSN 0903-1936

Hajat, S.; Anderson, H.R.; Atkinson, R.W. \& Haines, A. (2002). Effects of air pollution on general practitioner consultations for upper respiratory diseases in London. Occupational and Environmental Medicine, Vol. 59, No. 5, pp. 294-299, ISSN 14707926

Heikkinen, T. \& Jarvigen, A. (2003). The common cold. Lancet, Vol. 361, No. 9351, pp. 51-59, ISSN 0140-6736

Heinrich, J.; Hoelscher, B.; Frye, C.; Meyer, I.; Pitz, M.; Cyrys, J.; Wjst, M.; Neas, L. \& Wichmann, H.E. (2002). Improved air quality in reunified Germany and decreases in respiratory symptoms. Epidemiology, Vol. 13, No. 4, pp. 394-401, ISSN 1044-3983

Hollingwhorst, J.W.; Kleeberger, S.R. \& Forster, M.W. (2007). Ozone and pulmonary innate immunity. Proceedings of the American Thoracic Society, Vol. 4, No. 3, pp. 240-246, ISSN 1546-3222

Hollinghurst, S.; Gorst, C.; Fahey, T. \& Hay, A.D. (2008). Measuring the financial burden of acute cough in pre-school children: a cost of illness study. BMC Family Practice, 9:10. ISSN 1471-2296, Available from http:/ / www.biomedcentral.com/1471-2296/9/10

Huang, Y.T.; Li, Z.; Carter, J.D.; Soukup, J.M.; Schwartz, D. \& Yang, I.V. (2008) Fine ambient particles; induce oxidative stress and metal binding genes in human alveolar 
macrophages. American Journal of Respiratory Cell and Molecular Biology, Vol. 41, No. 5, pp. 544-552, ISSN 1044-1549

Jaakkola, J.J.K.; Paunio, M.; Virtanen, M. \& Heinonen, O.P. (1991). Low-level air pollution and upper respiratory infections in children. American Journal of Public Health, Vol. 81, No. 8, pp. 1060-1063, ISSN 0090-0036

Ko, F.W.S. \& Hui, D.S.C. (2010). Effects of air pollution on lung health. Clinical Pulmonary Medicine, Vol. 17, No. 6, pp. 300-304, ISSN 1068-0640

Larrieu, S.; Lefranc, A.; Gault, G.; Chatignoux, C.F.; Jouves, B. \& Filleul, L. (2009). Are the short-term effects of air pollution restricted to cardiorespiratory diseases. American Journal of Epidemiology, Vol. 169, No. 10, pp. 1201-1208, ISSN 0002-9262

Lippmann, M. \& Ito, K. (2005). Sulfur dioxide: In: Air quality guidelines. Global Update 2005, World Health Organization, pp. 395-420, WHO Office for Europe, ISBN 92-8902192-6, Copenhagen

Martins, L.C.; Latorre, M.R.D.O.; Saldiva, P.H.N. \& Braga, A.L.F. (2001). Air pollution and emergency room visits for upper airway respiratory infection in São Paulo city: evaluation of vehicle restriction. Revista Brasileira de Epidemiologia, Vol. 4, No. 3, pp. 220-229, ISSN 1415-790X

McCullag, P. \& Nelder, J.A. (1989). Generalized linear models (2nd edition), Chapman \& Hall, ISBN 0-412-31760-5, London

Mei, L.; Stieb, D.M. \& Chen, Y. (2005). Coarse particulate matter and hospitalization for respiratory infections in children younger than 15 years in Toronto: a casecrossover analysis. Pediatrics, Vol. 116, No. 2, pp. 235-240, ISSN 0031-4005

Min, Y.G.; Rhee, C.S.; Choo, M.J.; Song, H.K. \& Hong, S.C. (1994). Histopathologic changes in the olfactory epithelium in mice after exposures to sulfur dioxide. Acta Otolaryngologica, Vol. 114, No. 3, pp. 447-452, ISSN 0001-6489

Olivieri, D. \& Scoditti, E. (2005). Impact of environmental factors on lung defenses. Eur Respir Rev, Vol. 14, No. 4, pp. 51-56, ISSN 0905-9180

Peel, J.; Tolbert, P.E.; Klein, M.; Metzger, K.B.; Flanders, D.; Todd, K.; Mulholland, J.A.; Ryan, P.B. \& Frumkin, H. (2005). Ambient air pollution and respiratory emergency department visits. Epidemiology, Vol. 16, No. 2, pp. 164-174, ISSN 1044-3983

Perez, L.; Rapp, R. \& Kunzli, N. (2010). The year of the lung: outdoor air pollution and lung health. Swiss Medical Weekly, Vol. 140, pp. E1-E7, ISSN 1424-3997

Ponka, A. (1990). Absenteeism and respiratory disease among children and adults in Helsinki in relation to low-level air pollution and temperature. Environmental Research, Vol. 52, No. 1, pp 34-46, ISSN 0013-9351

Shusterman, D. (2011). The effects of air pollutants and irritants on the upper airways. Proceedings of the American Thoracic Society, Vol. 8, No. 1, pp. 101-105, ISSN 15463222

Vareille, M.; Kieninger, E.; Edwards, M.R. \& Regamey, N. (2011). The airway epithelium: soldier in the fight against respiratory viruses. Clinical Microbiology Reviews, Vol. 24, No. 1, pp. 210-229, ISSN 0893-8512

von Mutius, E.; Sherril, D.L.; Fritzsch, G.; Martinez, F.D. \& Lebowitz, M.D. (1995). European Respiratory Journal, Vol. 6, pp. 723-728, ISSN 0903-1936 
Wong, T.W.; Tam, W.; Yu, I.T.S.; Wun, Y.T.; Wong, A.H.S. \& Wong, C.M. (2006). Association between air pollution and general practitioner visits for respiratory diseases in Hong Kong. Thorax, Vol. 61, No. 7, pp. 585-591, ISSN 0040-6376 


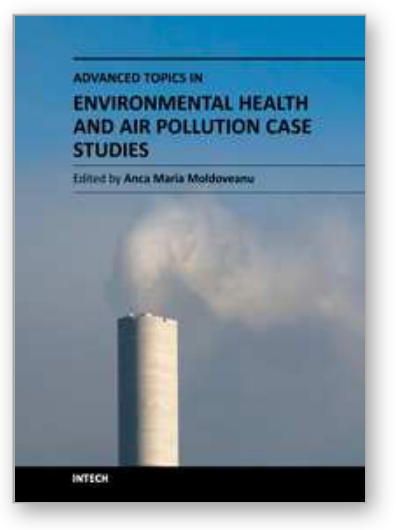

\section{Advanced Topics in Environmental Health and Air Pollution Case Studies \\ Edited by Prof. Anca Moldoveanu}

ISBN 978-953-307-525-9

Hard cover, 470 pages

Publisher InTech

Published online 29, August, 2011

Published in print edition August, 2011

The book describes the effects of air pollutants, from the indoor and outdoor spaces, on the human physiology. Air pollutants can influence inflammation biomarkers, can influence the pathogenesis of chronic cough, can influence reactive oxygen species (ROS) and can induce autonomic nervous system interactions that modulate cardiac oxidative stress and cardiac electrophysiological changes, can participate in the onset and exacerbation of upper respiratory and cardio-vascular diseases, can lead to the exacerbation of asthma and allergic diseases. The book also presents how the urban environment can influence and modify the impact of various pollutants on human health.

\section{How to reference}

In order to correctly reference this scholarly work, feel free to copy and paste the following:

Marcos Abdo Arbex, Silvia Leticia Santiago, Elisangela Providello Moyses, Luiz Alberto Pereira, Paulo Hilário Saldiva and Alfésio Luîs Ferreira Braga (2011). Impact of Urban Air Pollution on Acute Upper Respiratory Tract Infections, Advanced Topics in Environmental Health and Air Pollution Case Studies, Prof. Anca Moldoveanu (Ed.), ISBN: 978-953-307-525-9, InTech, Available from: http://www.intechopen.com/books/advanced-topicsin-environmental-health-and-air-pollution-case-studies/impact-of-urban-air-pollution-on-acute-upperrespiratory-tract-infections

\section{INTECH}

open science | open minds

\author{
InTech Europe \\ University Campus STeP Ri \\ Slavka Krautzeka 83/A \\ 51000 Rijeka, Croatia \\ Phone: +385 (51) 770447 \\ Fax: +385 (51) 686166 \\ www.intechopen.com
}

\author{
InTech China \\ Unit 405, Office Block, Hotel Equatorial Shanghai \\ No.65, Yan An Road (West), Shanghai, 200040, China \\ 中国上海市延安西路65号上海国际贵都大饭店办公楼 405 单元 \\ Phone: +86-21-62489820 \\ Fax: $+86-21-62489821$
}


(C) 2011 The Author(s). Licensee IntechOpen. This chapter is distributed under the terms of the Creative Commons Attribution-NonCommercialShareAlike-3.0 License, which permits use, distribution and reproduction for non-commercial purposes, provided the original is properly cited and derivative works building on this content are distributed under the same license. 